\title{
Malignant Lymphoma Originating in the Jejunum of a Long-term Follow-up Case of Protein-losing Enteropathy
}

\author{
Meiko Nishiuchi, Masato IIda, Yasuhiko SaIKa, Takahiro Kuwasako, Kouichi SeKI, \\ Yoshitake ShInJ, Isamu UKaI*, Tatsuya ShugINo* and Takashi KOHRO**
}

\begin{abstract}
A 50-year-old female patient, who had been followed for 15 years for protein-losing enteropathy, was hospitalized due to epigastric pain. Examination on admission revealed that the patient was in the sub-ileus state. On the 26th day after admission, she complained of severe abdominal pain and shortly after she went into shock. The emergency laparotomy documented intestinal perforation and a tumor. The perforated site was right at the middle of tumor. The histological and histochemical studies identified the tumor as malignant lymphoma of $B$ lymphocyte lineage. As far as we know, this is the third case of malignant lymphoma occurring in the jejunum in a patient with protein-losing enteropathy in Japan. The possible relationship between lymphomas and proteinlosing enteropathy is discussed.
\end{abstract}

(Internal Medicine 36: 556-560, 1997)

Key words: MALToma in the jejunum, perforation of the jejunum

\section{Introduction}

Both jejunal malignant lymphoma (non-Hodgkin lymphoma, NHL) and protein-losing enteropathy (PLE) are uncommon conditions in Japan. In one PLE patient whom we have been observing for 15 years, a NHL developed in the jejunum and was unrecognized until emergency surgery was performed for perforation of the jejunum. We report here this rare case of PLE complicated by NHL.

\section{Case Report}

A 50-year-old Japanese woman was admitted to our hospital with epigastralgia on April 14, 1995. She had a remote history of pulmonary tuberculosis at the age of 5 years. Her first visit to our clinic was in December 1979, when she had complained of edema of her lower extremities.

The blood test revealed marked hypoproteinemia $(3.5 \mathrm{~g} / \mathrm{dl})$. On January 25, 1980, she received laparoscopy examination and lymphangiectasis was found in the serosa of the intestine (Fig. 1). Considering the possibility of protein-losing enteropathy, a close examination was carried out at the 2 nd Department of Internal Medicine of Osaka University.

The X-ray examination of the small intestine using contrast media disclosed a diffusely granular mucosal pattern and no ulcer. At the same time, the Gordon test of her excrement revealed a value of $5.78 \%$ (normally 0 to $1.5 \%$ ) confirming copious leakage of protein into the excrement of the intestinal canal. Also noted on the plain abdominal X-ray film were calculous deposits of lymphatic glands attributable to the intestine tuberculosis she had suffered in her childhood, though no stricture of cysterna chyli was seen in the lymphographs. It was inferred that the loss of protein was caused by occlusion of lymphatics at the mesenteric membrane of the small intestine. Considering the fact that she showed an unusually high resolving rate of albumin of $28 \%$ per day (normally $11.4 \%$ ) and resolving volume of $16.5 \mathrm{~g} /$ day (normally $12.6 \mathrm{~g}$ ), we made a definitive diagnosis of protein-losing enteropathy.

Her hypoproteinemia continued and she was admitted 7 times for protein supplement. In December, 1994, epigastralgia achieved the state of subileus, ailments were alleviated and she left the hospital. And again in April 14 1995, due to epigastralgia, she was admitted.

The physical examination at admission revealed the following: she was $149 \mathrm{~cm}$ in height, $40 \mathrm{~kg}$ in weight, pulse rate $80 / \mathrm{min}$ and blood pressure of 102/80 $\mathrm{mmHg}$. The abdomen was markedly swollen, but an intestinal murmur was heard.

The post-admission examination (Table 1) revealed decreased serum total protein $(3.2 \mathrm{~g} / \mathrm{dl})$ and decreased albumin $(1.5 \mathrm{~g} / \mathrm{dl})$. All classes of serum immunoglobulins were severely

From the Department of Internal Medicine, *Critical Care Center and **Pathology, Hyogo Prefectural Nishinomiya Hospital, Nishinomiya Received for publication May 13, 1996; Accepted for publication April 3, 1997

Reprint requests should be addressed to Dr. Meiko Nishiuchi, the Department of Internal Medicine, Hyogo Prefectural Nishinomiya Hospital, 13-9 Rokutanji-cho Nishinomiya, 662 
decreased. Occult blood was present, though she was not anemic.

The plain radiography of the abdomen at this time (Fig. 2) revealed a marked gas image in the abdomen and obsolete calcareous deposits in the lower abdomen. We only administered fluid alimentation. However, on May 9, 1995 she suddenly went into shock resulting from severe abdominal pain. Analgesic medication was totally ineffective, and it was impossible to hear her intestinal murmur. An emergency operation was performed at the Critical Care Center of our hospital under a strong suspicion of perforation somewhere along the digestive

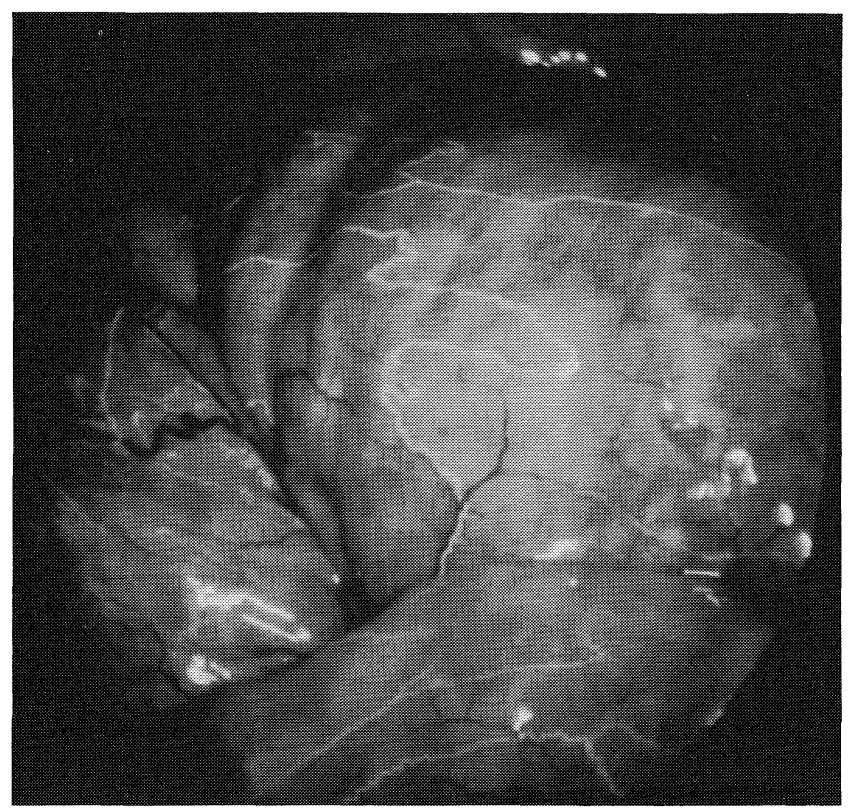

Figure 1. Laparoscopic view of the serosa of the intestinal canals (January 25,1980 ). We found a helix of dilated lymphatic vessels on the serosa of the intestine. tract.

The surgery revealed a perforated site in the jejunum located $120 \mathrm{~cm}$ distal to the ligament of Treitz. On opening the intestinal segment, an ulcerated tumor with a diameter of $5 \mathrm{~cm}$ was found in the mucosa.

The cut surface of the tumor gave a fish-flesh, sarcomatous appearance. The perforated site was at the base of the tumorulcer. The oral-to-tumor segment of the jejunum was dilated. Approximately $50 \mathrm{~cm}$ of the segment with the tumor at the center, was excised followed by an end-to-end anastomosis.

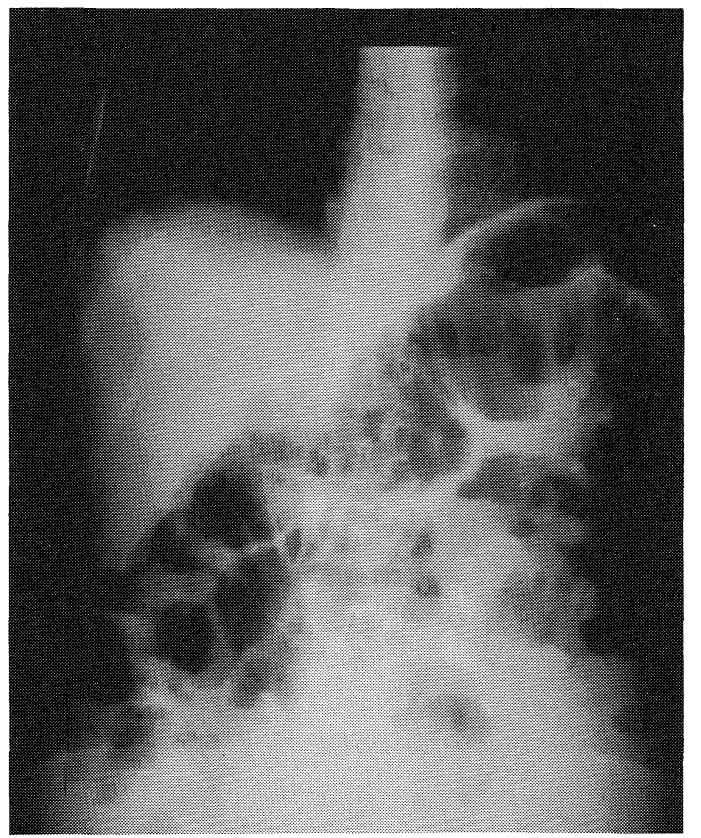

Figure 2. Plain radiograph of the abdomen on the last admission (April 17, 1995) revealing an increased volume of intestinal gas and obsolete calcification.

Table 1. Laboratory Findings on Admission (4/17/1995)

\begin{tabular}{lrlr}
\hline Complete blood cell count & & Blood chemical studies & \\
Red blood cell & $392 \times 10^{4} / \mu \mathrm{l}$ & Aspartate amino transferase & $19 \mathrm{U} / l$ \\
Hemoglobin & $11.3 \mathrm{~g} / \mathrm{dl}$ & Alanine amino transferase & $11 \mathrm{U} / l$ \\
Hematocrit & $34.4 \%$ & Alkaline phosphatase & $128 \mathrm{U} / l$ \\
White blood cell & $4,800 / \mu 1$ & $\gamma$-glutamyl transpeptidase & $5 \mathrm{U} / \mathrm{dl}$ \\
Platelet & $28.6 \times 10^{4} / \mu \mathrm{l}$ & Total protein & $3.2 \mathrm{~g} / \mathrm{dl}$ \\
Examination of feces & & Albumin & $1.5 \mathrm{~g} / \mathrm{dl}$ \\
Occult blood & $(+)$ & A/G & 0.86 \\
Serology & & Total cholesterol & $150 \mathrm{mg} / \mathrm{dl}$ \\
Microsome test & negative & FBS & $92 \mathrm{mg} / \mathrm{dl}$ \\
Thyroid test & negative & Na & $146 \mathrm{mEq} / l$ \\
Antinuclear antibody & Kositive $40 \mathrm{sp}$ & $\mathrm{K}$ & $3.6 \mathrm{mEq} / l$ \\
Anti-DNA & negative & $\mathrm{C}$-reactive protein & $113 \mathrm{mEq} / l$ \\
IgG & $571 \mathrm{mg} / \mathrm{dl}$ & & $0.1 \mathrm{mg} / \mathrm{dl}$ \\
IgA & $121 \mathrm{mg} / \mathrm{dl}$ & & \\
IgM & $34 \mathrm{mg} / \mathrm{dl}$ & & \\
\hline
\end{tabular}


A macrophoto of the strictured, perforated site of the excised specimen (Fig. 3), a loupe view of the same site (Fig. 4), and dilated lymphatic vessels of the mucosa of the jejunum (Fig. 5) are shown. The tumor, on microscopic examination, consisted of a diffuse proliferation of large lymphoma cells. Plasma cells with eccentrically located nuclei (Fig. 6), lymphoepithelial lesion; intraepithelial invasion of tumor cells (Fig. 7), and centrocyte-like cells with cleaved nuclei and clear cytoplasm (Fig. 8) were seen. Immunohistochemically the tumor cells stained with L-26, but not with UCHL-1, indicating that the tumor cells were of B lymphocyte lineage. Based on these findings, the tumor was considered to be a marginal zone B-cell lymphoma, extranodal (MALToma) according to Real's classification (1) at stage 1.

After the surgery, the patient survived the suppurative peritonitis and its sequelae such as disseminated intravascular coagulation (DIC) by intensive protein supplement and antibiotics. No further anti-tumor therapy was instituted. Oral alimentation was resumed on May 27 and she was discharged from the hospital on June 24, 1995. At present (as of October 1996), she can eat an ordinary diet and lives in good health though her serum protein level remains low $(4.2 \mathrm{mg} / \mathrm{dl})$.

\section{Discussion}

The primary digestive tract lymphoma is extranodal, and jejunum and ileum are organs in which lymphoma occurs more frequently than any other part except for the stomach. In 1984, Isaacson and Wright (2) reported on a particular extranodal lymphoma with low grade malignancy derived from mucosaassociated lymphoid tissue (MALT), which they termed MALToma, occurring in the lung, salivary gland, thyroid gland, bladder, pharynx and skin (3-5); although in most cases it originates in the enterogastric canals.

Awrich et al (6) reported 18 cases of malignant lymphoma among 82 cases of malignant tumor of the small intestine over 25 years of observation. The most common complaints accompanying malignant lymphoma of the intestine were pain, obstruction, mass formation and hemorrhaging. Of the small intestine patients, 29 were anemic and 57 were hypoalbuminemic; 44 had stools positive for occult blood. At the time of diagnosis, they were all at the advanced stage. AlMondhiry (7) reported that lymphoma accounted for 10-40\% of the cases of malignant tumor of the small intestine. Of 46 cases of lymphoma, 25 cases involved the ileum and 8 cases, the jejunum. Lymphoma was scarcely found in the jejunum.

On the other hand, protein-losing enteropathy (8) is a general term for various diseases characterized by hypoproteinemia caused by intracanal leakage of serum protein. Important factors for diagnosing protein-losing enteropathy are verification of low serum protein and protein leakage into the digestive tract, and dilatation of lymphatic vessels of the small intestine. In the present case, we confirmed lymphangiectasis in the serosal membrane of the jejunum during the surgery, although the lymphagiectasis and the loss of protein into excrement had been already documented 15 years previously by laparoscopy and

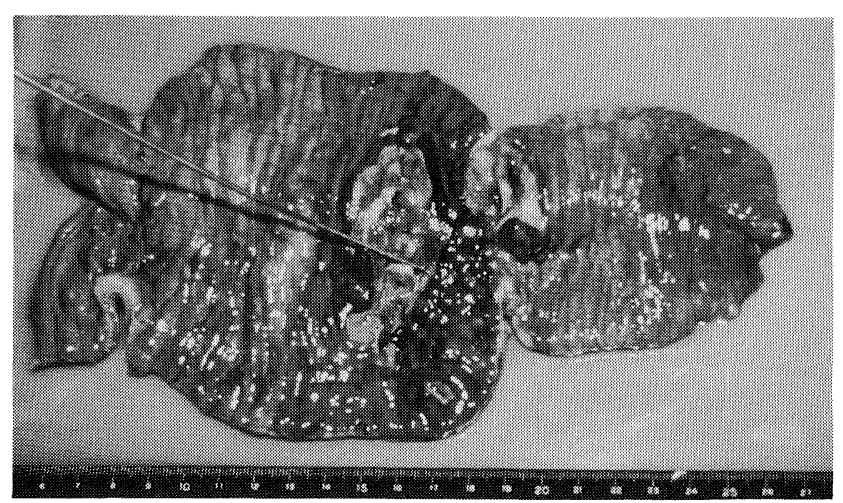

Figure 3. An ulcerated tumor (5 cm in diameter) was found at the center of the $50 \mathrm{~cm}$ long jejunal segment. The probe indicates the site of perforation.

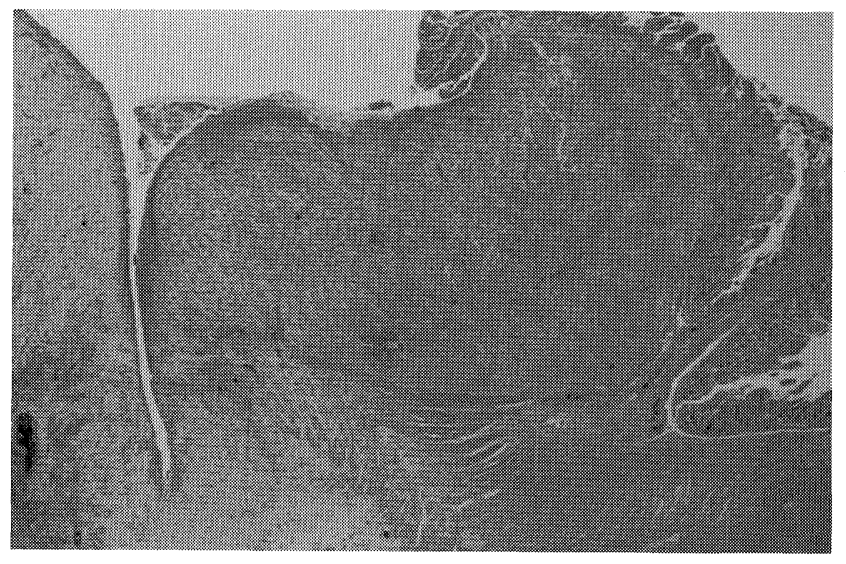

Figure 4. Loupe image of the tumor involving the entire thickness of the intestinal wall.

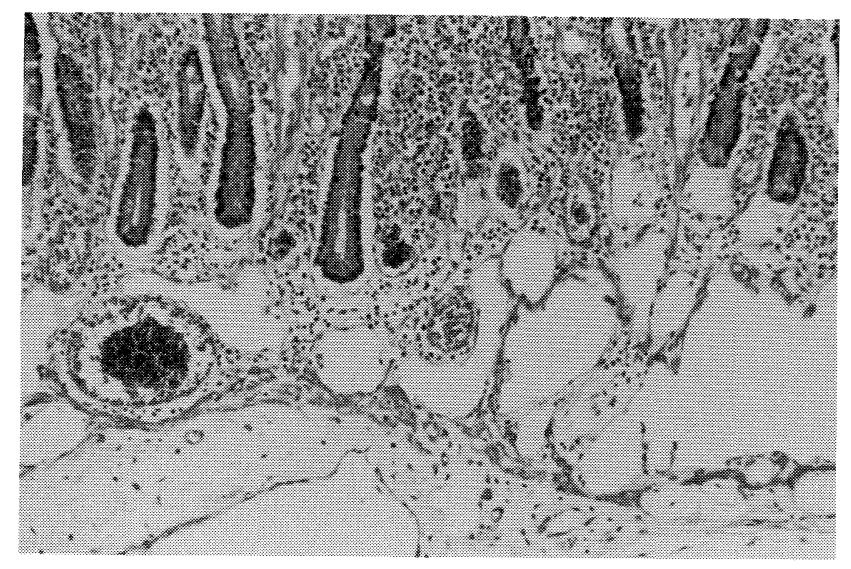

Figure 5. Jejunal mucosa containing dilated lymphatic vessels. 


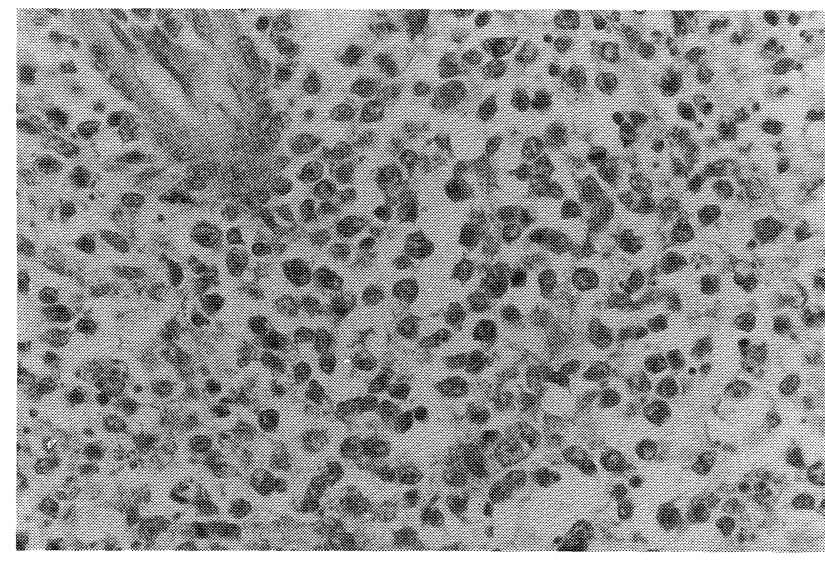

Figure 6. High power microscopic view of plasma cells with eccentrically located nuclei $($ HE stain, $\times 200)$.

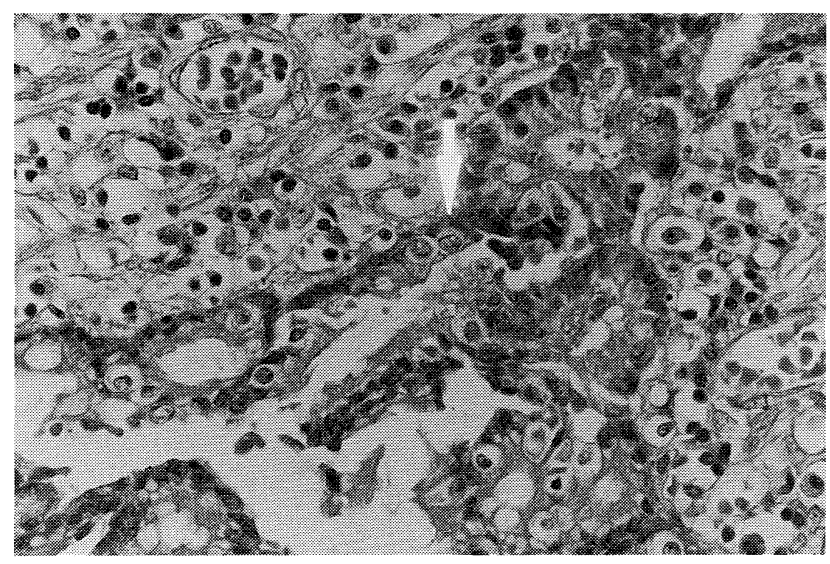

Figure 7. High power microscopic view of lymphoepithelial lesion; intraepithelial invasion of tumor cells (arrow) (HE stain, $\times 200$ ).

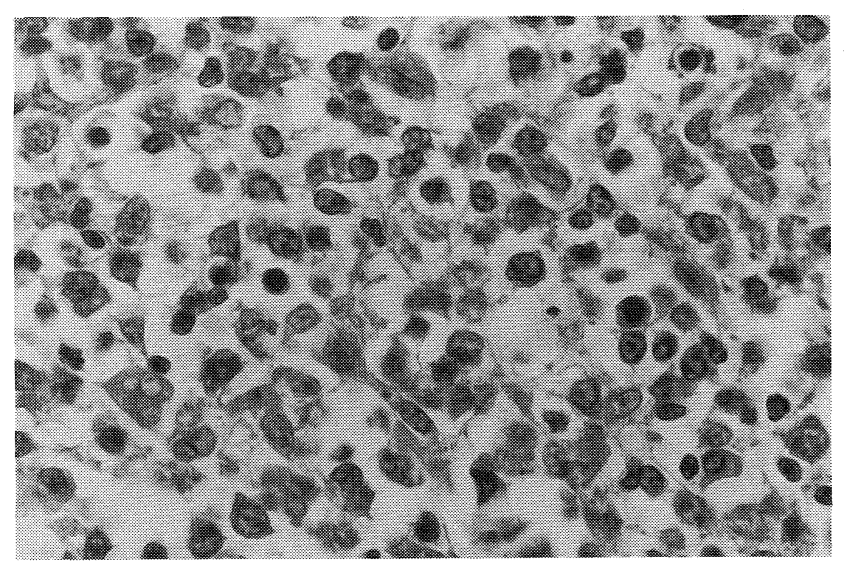

Figure 8. High power microscopic view of centrocyte-like cells with cleaved nuclei and clear cytoplasm (HE stain, $\times \mathbf{4 0 0}$ ).
Gordon test, respectively.

In a study on lymphangiectasia intestinalis of the lymphatic vessel system, Nishikawa (9) described the intestinal lymphatic vessels generally running together to flow into the cisterna chyli through the lymphatics of the mesenteric membrane. The vessels from the lower limbs ascend to the retroperitoneal cavity toward the aorta. They then ascend along the side of the spine bilateral to meet the intestinal lymph in the cistern from the cisterna chyli. Intestinal lymph goes up within the thoracic cavity to flow into the left subclavian vein. If occlusion is present anywhere along the pathway from the intestine to the lymphatics at the mesenteric membrane, cistern, thoracic duct, or vein, lymph retention develops towards the periphery, which finally causes lymphangiectasia intestinalis. In a study on a 38year-old male, Nishikawa (9) reported finding abdominal dropsy and a dilated serpiginous lymphatic vessel on the surface of the serosal membrane during laparoscopy. Fibrous adhesion was found at the site where the cisterna chyli flowed into the left subclavian vein. The lymph retention was relieved when the site was cut and the thoracic duct was anastomosed to the subclavian vein. Nishikawa (9) suggested that fibrous adhesions might have been caused at the area of retention during the course of healing of cicatrization of tuberculous lymphadenitis in the supraclavicular cavity. In the present cases, the subject had past history of tuberculosis, and her radiograph of 15 previously revealed extensive calcification in the abdomen. The lymphography at that time revealed no occlusion in the major lymphatic vessels. Possibly stricture of the calcified tubercles in the mesenteric membrane might have caused lymphangiectasia intestinalis. However, this is a mere speculation. Waldmann (8) suggested that lymphangiectasia intestinalis might develop as a result of acquired changes following acute pancreatitis, retroperitoneal fibrosis or lymphoma, or as a result of congenital abnormalities. However, primary intestinal lymphangiecta is very rare. Heresbach et al (10) undertook detailed immunological study on biopsies from the duodenum and terminal ileum obtained from 2 cases of primary intestinal lymphangiectasia and found humoral and cellular deficiency. This drew attention to its association with lymphoma.

Mathus-Vliegen et al (11) traced 14 cases of enteropathyassociated lymphoma, and reported that 10 of these cases had a history of celiac disease. The frozen sections obtained during laparotomy were studied by immunological stain. As a result, they reported that patients with a history celiac disease easily develop malignant lymphoma: Malignant lymphoma was found in $60-66 \%$ of the patients with an average 8-year history of celiac disease.

The 1992 clinical statistics in Japan revealed that only 1 out of 63 cases of protein-losing enteropathy complicated by malignant lymphoma of the small intestine. The second patient was a male (52 years) who underwent surgery 3 years after being diagnosed with protein-losing enteropathy. The present patient is the third case.

Wright (12) and Howell et al (13) concluded that malignant lymphoma might be the major complication of celiac disease. 


\section{NisHIUCHI et al}

In the present case, the X-ray examination of 15 years ago of the small intestine using contrast media disclosed a diffusely granular mucosal pattern, but no ulcer. However, we consider that lymphangiectasia intestinalis might be a kind of maldigestion or malabsorption syndrome, caused by insufficient intestinal absorption. Protein-losing enteropathy and massive loss of the lymphocytes from the intestinal lymphatic vessels resulted in reduction of cellular immunity, with a marked decrease of $\mathrm{T}$ lymphocytes. Therefore, in the present case, the development of NHL in a rare site such as the jejunum may be related to the 15-year long state of hypoproteinemia and hypoimmunoglobulinemia, which could have led to gradual deterioration of the immune mechanism. During the 15 years of observation of this patient, there had been no abdominal distress until December 1994. However, at the time of the examination 15 years ago, a silent lymphoma, not yet diagnosable, might have been present as lymphangiectasis, and persisted and ultimately caused lymph edema in the intestine due to the loss of protein which prolonged the enteropathy-like celiac disease.

\section{References}

1) Harris NL, Jaffe ES, Stein H, et al. A revised European-American classification of lymphoid neoplasms: a proposal from the International Lymphoma Study Group. Blood 84: 1361, 1994 (see comments).
2) Isaacson $\mathrm{P}$, Wright $\mathrm{DH}$. Extranodal malignant lymphoma arising from mucosa-associated lymphoid tissue. Cancer 53: 2515, 1984.

3) Isaacson PG, Spender J. Malignant lymphoma of mucosa-associated lymphoid tissue. Histopathology 11: 445, 1987.

4) Harris NL. Extranodural lymphoid infiltrates and mucosa-associated lymphoid tissue (MALT). A unifying concept. Am J Surg Pathol 15: 879, 1991 (editorial; see comments).

5) Wotherspoon AC, Doglioni C, Isaacson PG. Low-grade gastric B-cell lymphoma of mucosa-associated lymphoid tissue (MALT): a multifocal disease. Histopathology 20: 29, 1992.

6) Awrich AE, Irish CE, Vetto RM, Fletcher WS. A twenty-five year experience with primary malignant tumors of the small intestine. Surg Gyneco Obstet 151: 9, 1980.

7) Al-Mondhiry H. Primary lymphomas of the small intestine: east-west contrast. Am J Hematol 22: 89, 1986.

8) Waldmann TA. Protein-losing enteropathy. Gastroenterology 50: 422, 1966.

9) Nishikawa M. Protein losing enteropathy. Naika 28: 1056, 1971.

10) Heresbach $D$, Raoul JL, Genetet $N$, et al. Immunological study in primary intestinal lymphangiectasia. Digestion 55: 59, 1994.

11) Mathus-Vliegen EM, Van Halteren H, Tytgat GN. Malignant lymphoma in coeliac disease: various manifestations with distinct symptomatology and prognosis? J Intern Med 236: 43, 1994.

12) Wright DH. The major complications of coeliac disease. Baillieres Clin Gastroenterol 9: 351, 1995.

13) Howell WH, Leung ST, Jones DB, HLA-DRB, -DQA and DQB polymorphism in celiac disease and enteropathy-associated T-cell lymphoma, common features and additional risk factors for malignancy. Hum Immunol 43: 29, 1995. 